\title{
Hydrostatic drives as safe and energy saving machines
}

\section{The drive investigation method compatible with the diagram of power increase opposite to the direction of power flow}

\author{
Zygmunt Paszota, Prof. \\ Gdansk University of Technology
}

\begin{abstract}
Designers and manufacturers of hydrostatic drives have not a tool for precise determination of their energy efficiency, changing in a wide range in the driven device operating field, i.e. in the full range of the hydraulic motor speed and load and the working medium viscosity. This applies both to determining of losses and energy efficiency of displacement machines (pump and hydraulic motor) used in the drive system, and to losses and energy efficiency of the motor control system structure. A method is proposed compatible with the diagram of power increase opposite to the direction of power flow. That diagram replaces the Sankey diagram of power decrease in the direction of power flow.
\end{abstract}

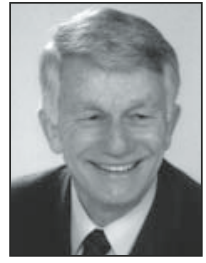

Key words: hydrostatic drive and control; evaluation of energy losses; method of the energy efficiency investigation; search for the energy saving solutions

\section{INTRODUCTION}

Hydrostatic drive and control system have been in use for decades in ships and ocean technology objects, mainly because they are safe.

For instance, in tankers, because of the danger of explosion, the deck equipment - anchor windlass, automatic mooring winches etc. - are equipped with the hydrostatic drive. Cargo valves along the ship have hydrostatic remote control from the central console. The transport (impeller) pump system for oil unloading is often driven by displacement hydraulic motors submerged in the tanks.

In bulk carriers the hydrostatic drive is used for large hatch covers, deck cranes and other deck equipment.

Tankers and bulk carriers (and also other ships) have the hydrostatic drive and control systems for steering gear, bilge, ballast and fuel valves, cranes, hull opening covers and also the hydrostatic control of controllable pitch propellers in the ship main propulsion system.

In tankers and bulk carriers the central hydrostatic systems are used of simultaneous drive and control of many devices with total power of several megawatts.

A specific feature of the roll on - roll off ships are hydrostatically driven transport devices. A typical example is the stern ramp, $50 \mathrm{~m}$ long and $22 \mathrm{~m}$ wide close to the hull, and also internal ramps between decks.
In the container carriers a typical example are deck cranes with $450 \mathrm{kN}$ lift capacity and $30 \mathrm{~m}$ or more outreach, with separate hydrostatic drive in three independent closed circuits of hoisting, turning and change of outreach.

Fishing ships of up to $30 \mathrm{~m}$ in length are equipped with hydrostatically driven trawl, net and auxiliary winches. Multitask trawlers of up to $50 \mathrm{~m}$ in length, seiners up to $80 \mathrm{~m}$ long for catching fish in shoals in the ocean depth have hydrostatically driven winches; the hydrostatic drive is also used in cranes, auxiliary winches, hatch covers and other centrally controlled devices.

On the platforms, drilling, production and auxiliary ships, e.g. ocean tugs, the deck and technological equipment has most often the hydrostatic drive and control because of the danger of explosion.

However, the above given examples of the use of hydrostatic drive in floating units do not suggest that the hydrostatically driven ship and ocean object equipment will be dominating also in the future.

In 2006, the MacGREGOR company introduced, apart from deck cranes with hydrostatic drive, the first deck crane with electric drive [1]. In 2010 that company equipped only with $30 \mathrm{t}$ electric cranes 8 bulk carriers of 16900 DWT capacity ordered in China by the Polish Polsteam owner [2]. The advantages, pointed out by the manufacturer, compared with hydrostatically driven cranes, are the following: 
- faster and more precise positioning of the hook, reducing the loading time by $20 \%$ and shortening the port time, - the drive power smaller by $30 \div 35 \%$.

Also proposed is the use of electric drive and control of hatch covers in bulk carriers as well as full electric control of the ro - ro ship equipment.

The manufacturers of electrically driven ship equipment consider the energy efficiency of electric drive definitely higher than the hydrostatic drive efficiency.

The above quoted comparison of the installed power and energy efficiency of electric and hydrostatic drive is made in the situation when designer of a hydrostatically driven device has no tool for precise determination of the drive energy efficiency changing in a wide range in the driven device operating field. Therefore, there is no possibility of precise determining of the required power and in consequence of a reliable comparison of the two drives. This applies to the losses and energy efficiency of displacement machines (pump and hydraulic motor) used in the drive system and also to the energy efficiency of the whole system as a consequence of the used motor speed control structure.

In a hydrostatic drive system the mechanical energy is converted in the displacement pump into pressure energy of viscous fluid and the fluid pressure energy is converted into mechanical energy in the hydraulic motor. These two energy conversions in the displacement machines are connected with energy losses; the losses occur also in the conduits and in the motor speed throttling control assembly with a determined structure.

The only way is correct assessment of the level and proportion of energy losses, allowing also to search for energy saving solutions of the pump and motor as well as the whole hydrostatic drive system.

\section{DETERMINING OF THE ENERGY LOSSES WITH THE ROTATIONAL HYDRAULIC MOTOR INVESTIGATION AS AN EXAMPLE}

The excerpts of the reference [19] will be quoted and supplemented in chapter 3 with significant findings.

Correct evaluation of the energy behaviour of a hydraulic motor is an evaluation of its overall efficiency $\eta_{M}=f\left(n_{M}, M_{M}\right.$, $v)$, i.e. evaluation of the overall efficiency $\eta_{M}$ as a function of the motor shaft speed $n_{M}$ and load $M_{M}$ and of the working fluid viscosity $v$. This is also assessment of the value and proportions of the motor mechanical, volumetric and pressure losses deciding of the motor mechanical $\eta_{\mathrm{Mm}}$, volumetric $\eta_{\mathrm{Mv}}$ and pressure $\eta_{\mathrm{Mp}}$ efficiency, where the product $\eta_{\mathrm{M}}=\eta_{\mathrm{Mm}} \eta_{\mathrm{Mv}} \eta_{\mathrm{Mp}}$ determines the motor overall efficiency $\eta_{\mathrm{M}}$. The energy losses and the corresponding efficiencies $\eta_{\mathrm{Mm}}, \eta_{\mathrm{Mv}}$ and $\eta_{\mathrm{Mp}}$ should be determined as a function of parameters having a direct impact on the particular losses and efficiencies.

However, designers and makers of rotational hydraulic motors and hydrostatic systems have not had so far a tool to determine their energy behaviour in the $\left(0 \leq \bar{\omega}_{\mathrm{M}}\left\langle\bar{\omega}_{\mathrm{M}_{\max }}\right.\right.$, $0 \leq \overline{\mathrm{M}}_{\mathrm{M}}\left\langle\overline{\mathrm{M}}_{\mathrm{M}_{\max }}\right)$ field of change of the hydraulic motor shaft speed and load coefficients and in the $v_{\min } \leq v \leq v_{\max }$ field of change of the hydraulic oil viscosity.

The rotational motor producers make erroneous routine evaluations of the following energy efficiencies and work parameters:

- the motor overall efficiency $\eta_{M}$ as a function of the shaft speed $\mathrm{n}_{\mathrm{M}}$ and motor pressure decrease $\Delta \mathrm{p}_{\mathrm{M}}$ (e.g. $[11 \div$ 14]),
- the motor overall efficiency $\eta_{M}$ as a product of the volumetric efficiency $\eta_{\mathrm{Mv}}$ and the so called motor ,mechanical - hydraulic efficiency" $\eta_{\mathrm{Mmh}}$, all the three determined as a function of the same parameters (e.g. $[11,12])$,

- motor shaft speed $n_{M}$ as a function of the motor capacity $Q_{M}$ and volumetric efficiency $\eta_{\mathrm{Mv}}$, determined in turn as a function of the motor pressure decrease $\Delta \mathrm{p}_{\mathrm{M}}$ (e.g. $\left.[11,13]\right)$,

- motor shaft torque $\mathrm{M}_{\mathrm{M}}$ as a function of pressure decrease $\Delta \mathrm{p}_{\mathrm{M}}$ and the so called ",mechanical - hydraulic efficiency" $\eta_{\mathrm{Mmh}}$ of the motor (e.g. $[11 \div 14]$ ),

- motor capacity $Q_{M}$ as a function of the shaft speed $n_{M}$ and volumetric efficiency $\eta_{\mathrm{Mv}}$, determined in turn as a function of the motor pressure decrease $\Delta \mathrm{p}_{\mathrm{M}}$ (e.g. $\left.[11 \div 13]\right)$,

- motor shaft useful power $\mathrm{P}_{\mathrm{Mu}}$ as a function of the motor capacity $\mathrm{Q}_{\mathrm{M}}$ and pressure decrease $\Delta \mathrm{p}_{\mathrm{M}}$ and as a function of the motor overall efficiency $\eta_{\mathrm{M}}$ determined in turn as a function of the motor shaft speed $\mathrm{n}_{\mathrm{M}}$ and pressure decrease $\Delta \mathrm{p}_{\mathrm{M}}(\mathrm{e} . \mathrm{g} .[11 \div 13])$.

The hydraulic motor researchers evaluate in a wrong way the losses arising in the motor:

- the motor torque $\mathrm{M}_{\mathrm{Mm}}$ of mechanical losses as a function of the motor pressure decrease $\Delta \mathrm{p}_{\mathrm{M}}$ and shaft speed $\mathrm{n}_{\mathrm{M}}$, a sum of torque $\mathrm{M}_{\mathrm{Mm}}$ of mechanical losses and the so called ,torque of pressure losses" (resulting from the pressure losses $\Delta \mathrm{p}_{\mathrm{Mp}}$ in the motor) - as a function of motor pressure decrease $\Delta \mathrm{p}_{\mathrm{M}}$ and the shaft speed $\mathrm{n}_{\mathrm{M}}$,

- the intensity $\mathrm{Q}_{\mathrm{Mv}}$ of volumetric losses in the motor as a function of the motor pressure decrease $\Delta \mathrm{p}_{\mathrm{M}}$ (or as a function of the motor shaft torque $\mathrm{M}_{\mathrm{M}}$ ) and as a function of the motor shaft speed $n_{M}$.

The evaluation methods of the energy losses and efficiency of the rotational hydraulic motors, used so far in the scientific research and in the industrial practice, give wrong results because the parameters that the losses and efficiencies are a function of are themselves dependent of those losses.

There is very little information of the motor makers presenting properly the motor overall efficiency $\eta_{M}=f\left(n_{M}\right.$, $M_{M}$ ) as a function of the motor shaft speed $n_{M}$ and torque $M_{M}$ at a specified fluid viscosity $v$ and presenting the impact of viscosity $v$ on the overall efficiency $\eta_{M}$ (e.g. [10]).

It is a common deficiency that no information is given about the dependence of the motor mechanical, volumetric and pressure losses on the kinematic viscosity $v$ of the working fluid used in the hydrostatic drive system.

The fundamental reason of the erroneous evaluations are commonly accepted views on the research methodology and on the method of determining the energy losses in pumps and in hydraulic motors. That method is based, among others, on the traditional reading of the energy balance of a hydrostatic drive system from the Sankey diagram $[3 \div 9]$. The present unsatisfactory state is also an effect of using simplified evaluations of the relations of particular losses to the motor or pump working parameters and to the working fluid viscosity.

In reference [19] the work parameters, power, losses and energy efficiencies in a rotational hydraulic motor are defined and described by means of 46 expressions and also their complex interrelations are shown.

The end formula (46) presents the motor efficiency $\eta_{M}$ as a product of efficiencies described by means of losses and parameters deciding about those efficiencies, and the pressure decrease $\Delta \mathrm{p}_{\mathrm{Mi}}$ indicated in the motor working chambers and capacity $\mathrm{Q}_{\mathrm{M}}$ in the motor chambers are also functions of the losses: 

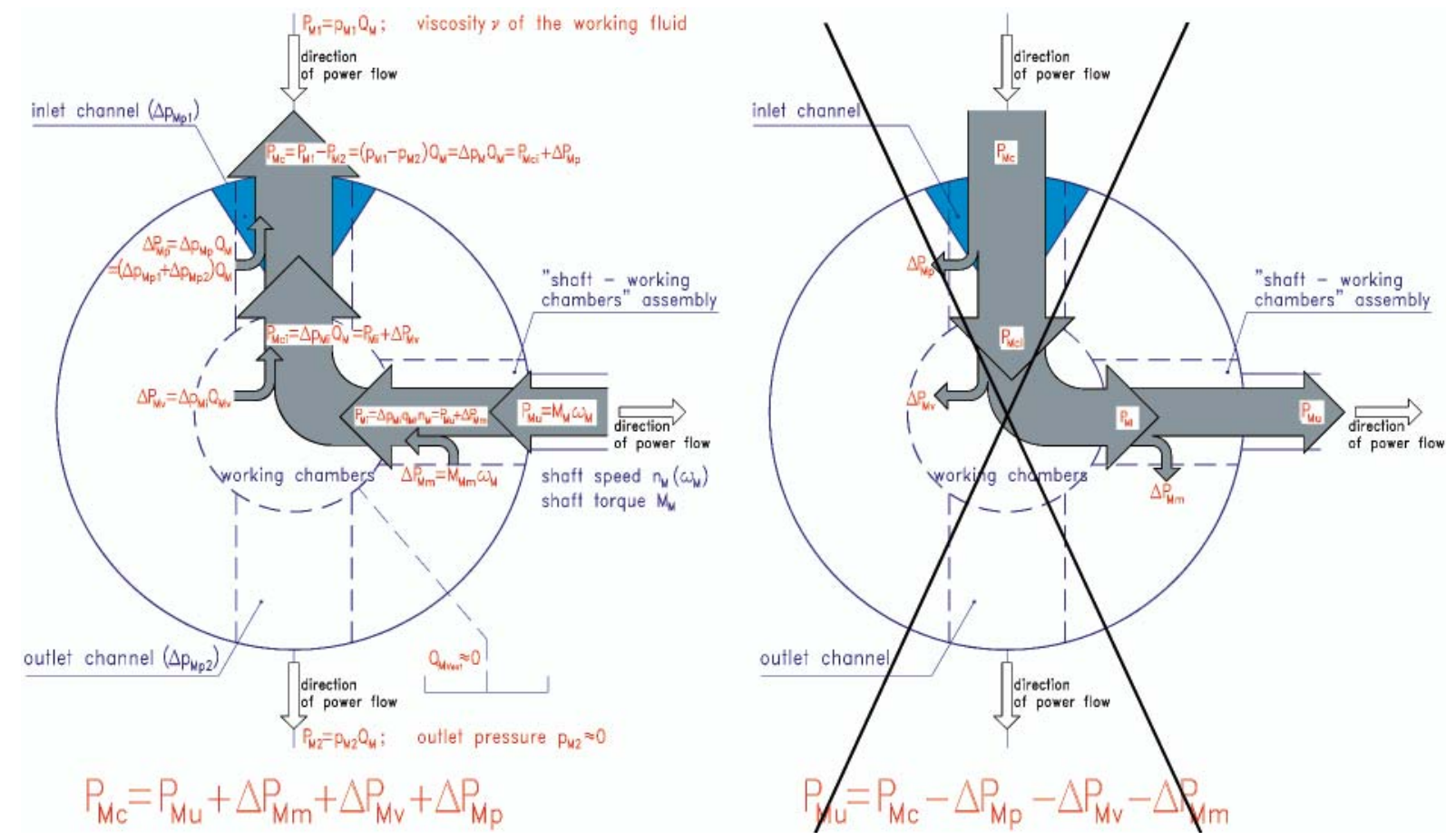

Fig. 1. Diagram of power increase in a hydraulic motor opposite to the direction of power flow, replacing the Sankey diagram of power decrease in the direction of power flow

where:

$$
\begin{gathered}
\eta_{M}=f\left(M_{M}, n_{M}, v\right)=\eta_{M m} \eta_{M v} \eta_{M p}= \\
=\frac{M_{M}}{M_{M}+M_{M m}} \frac{q_{M t} n_{M}}{q_{M t} n_{M}+Q_{M v}} \frac{\Delta p_{M i}}{\Delta p_{M i}+\Delta p_{M p}}
\end{gathered}
$$

$\mathrm{M}_{\mathrm{Mm}}=\mathrm{f}\left(\mathrm{M}_{\mathrm{M}}, \mathrm{n}_{\mathrm{M}}, v\right) \quad$ [equation (2)],

$\mathrm{Q}_{\mathrm{Mv}}=\mathrm{f}\left(\Delta \mathrm{p}_{\mathrm{Mi}}, \mathrm{n}_{\mathrm{M}}, v\right) \quad$ [equation (14)],

$\Delta \mathrm{p}_{\mathrm{Mp}}=\mathrm{f}\left(\mathrm{Q}_{\mathrm{M}}, v\right) \quad$ [equation (25)],

with:

$$
\Delta \mathrm{p}_{\mathrm{Mi}}=\frac{2 \Pi\left(\mathrm{M}_{\mathrm{M}}+\mathrm{M}_{\mathrm{Mm}}\right)}{\mathrm{q}_{\mathrm{Mt}}}[\text { equation (6)] }
$$

and

$$
\mathrm{Q}_{\mathrm{M}}=\mathrm{q}_{\mathrm{Mt}} \mathrm{n}_{\mathrm{M}}+\mathrm{Q}_{\mathrm{Mv}} \text { [equation (16)] }
$$

Decrease $\Delta \mathrm{p}_{\mathrm{Mi}}$ of pressure indicated in the working chambers (equation (6)) is a function of the loading torque $\mathrm{M}_{\mathrm{M}}$ and torque $\mathrm{M}_{\mathrm{Mm}}$ of mechanical losses in the ,shaft - working chambers" assembly. Capacity $\mathrm{Q}_{\mathrm{M}}$ in the motor channels (equation (16)) is a function of the motor shaft speed $n_{M}$ and the intensity $Q_{M v}$ of volumetric losses in the working chambers.

\section{POWER IN THE DRIVE SYSTEM, LOSSES AND ENERGY EFFICIENCY, SYSTEM OPERATING FIELD}

\section{Diagram of power increase in a power transmission system \\ opposite to the direction of power flow} replaces

the Sankey diagram of power decrease in the direction of power flow.

The Sankey diagram is the fundamental cause of incorrect evaluation of losses in a drive system.

The Sankey diagram connected with a drive system suggests an evaluation defining the output power of the system as a difference between the system input power and sum of the powers of losses occurring in the system. Therefore the energy losses in the system are evaluated as a function of parameters describing the input power.

In accordance with the proposed diagram of power increase in a power transmission system opposite to the direction of power flow, the system input power is a sum of the system output power and powers of losses occurring in the system. The energy losses in the system are evaluated as a function of parameters describing the system output power.

Fig. 1 illustrates this principle by an example of power flow in a hydraulic motor.

The power $\mathrm{P}_{\mathrm{Mc}}$ consumed by the hydraulic motor is a sum of motor shaft useful power $\mathrm{P}_{\mathrm{Mu}}$ and powers of three different energy losses in the motor. The losses occur in series increasing power in the opposite direction to the direction of power flow. In effect, the power in the motor increases from the shaft useful power $\mathrm{P}_{\mathrm{Mu}}$ to the working fluid power $\mathrm{P}_{\mathrm{Mc}}$ consumed by the motor:

$$
\mathrm{P}_{\mathrm{Mc}}=\mathrm{P}_{\mathrm{Mu}}+\Delta \mathrm{P}_{\mathrm{Mm}}+\Delta \mathrm{P}_{\mathrm{Mv}}+\Delta \mathrm{P}_{\mathrm{Mp}}
$$

Mechanical losses (and power $\Delta \mathrm{P}_{\mathrm{Mm}}$ of mechanical losses) occur in the ,shaft - working chambers" assembly.

Volumetric losses (and power $\Delta \mathrm{P}_{\mathrm{Mv}}$ of volumetric losses) occur in the working chambers.

Pressure losses (and power $\Delta \mathrm{P}_{\mathrm{Mp}}$ of pressure losses) occur in the motor channels.

Formula (46) (equation (2)) shows a direct dependence of the torque $\mathrm{M}_{\mathrm{Mm}}$ of mechanical losses in the ,shaft - working chambers" assembly on the torque $\mathrm{M}_{\mathrm{M}}$ and on the motor shaft rotational speed $n_{M}$ as well as on the working fluid viscosity $v$.

Formula (46) (equations $(14,6)$ ) presents a complex dependence of the intensity $\mathrm{Q}_{\mathrm{Mv}}$ of volumetric losses in the working chambers on the shaft loading torque $\mathrm{M}_{\mathrm{M}}$ and on the torque $\mathrm{M}_{\mathrm{Mm}}$ of mechanical losses in the ,shaft - working chambers" assembly (decrease $\Delta \mathrm{p}_{\mathrm{Mi}}$ of pressure indicated in the working chambers depends on $\mathrm{M}_{\mathrm{M}}$ and $\mathrm{M}_{\mathrm{Mm}}$ and has direct impact on $\mathrm{Q}_{\mathrm{Mv}}$ ) and also on the shaft speed $\mathrm{n}_{\mathrm{M}}$ (influencing in a diversified way the torque $\mathrm{M}_{\mathrm{Mm}}$ of mechanical losses (2) and 
intensity $\mathrm{Q}_{\mathrm{Mv}}$ of volumetric losses (14)). The intensity $\mathrm{Q}_{\mathrm{Mv}}$ of volumetric losses depends on a diversified impact of the working fluid viscosity $v$ : indirectly by impact of $v$ on the torque $\mathrm{M}_{\mathrm{Mm}}$ of mechanical losses in the ,shaft - working chambers" assembly (2) and directly by impact of $v$ on the intensity $\mathrm{Q}_{\mathrm{Mv}}$ of losses in the working chambers (14).

Formula (46) (equations $(25,16,14,6))$ presents also a complex dependence of losses $\Delta \mathrm{p}_{\mathrm{up}}$ of pressure in the motor channels on the motor shaft rotational speed $n_{M}$ and on intensity $\mathrm{Q}_{\mathrm{Mv}}$ of volumetric losses in the motor working chambers. The intensity $\mathrm{Q}_{\mathrm{Mv}}$ of volumetric losses influences the motor capacity $\mathrm{Q}_{\mathrm{M}}$ (equation (16)) and at the same time $\mathrm{Q}_{\mathrm{Mv}}$ depends in a complex way on the shaft loading torque $\mathrm{M}_{\mathrm{M}}$ and on the torque $\mathrm{M}_{\mathrm{Mm}}$ of mechanical losses in the motor ,shaft - working chambers" assembly. Pressure losses $\Delta \mathrm{p}_{\mathrm{Mp}}$ in the motor channels are also dependent on the diversified impact of the working fluid viscosity $v$ : indirectly by impact of $v$ on the torque $M_{M m}$ of mechanical losses in the ,shaft - working chambers” assembly (2) and by impact of $v$ on the intensity $\mathrm{Q}_{\mathrm{Mv}}$ of volumetric losses in the working chambers (14) and directly by impact of $v$ on the losses $\Delta \mathrm{p}_{\mathrm{Mp}}$ of pressure in the channels (25).

Contrary to the commonly used, both by manufacturers and researchers, methods of evaluation of the hydraulic motor losses, it is unacceptable to create a „sum" of the torque $\mathrm{M}_{\mathrm{Mm}}$ of mechanical losses in the „shaft - working chambers” assembly and the „torque" of pressure losses $\Delta \mathrm{p}_{\mathrm{Mp}}$ in the motor channels, and also such a „sum" must not be evaluated as directly dependent on the same chosen parameters, because those losses are of different character and depend on different parameters:

$$
\begin{gathered}
\mathrm{M}_{\mathrm{Mm}}=\mathrm{f}\left(\mathrm{M}_{\mathrm{M}}, \mathrm{n}_{\mathrm{M}}, v\right) \\
\Delta \mathrm{p}_{\mathrm{Mp}}=\mathrm{f}\left(\mathrm{Q}_{\mathrm{M}}, v\right)
\end{gathered}
$$

The impact of hydraulic oil viscosity $v$ on the energy losses in a hydraulic motor, i.e. on:

- torque $M_{\mathrm{Mm}}$ of mechanical losses in a ,shaft - working chambers" assembly,

- intensity $Q_{M v}$ of volumetric losses in the working chambers,

- pressure losses $\Delta \mathbf{p}_{\mathrm{Mp}}$ in the conduits,

$$
\text { is diversified. }
$$

Dependence of the motor losses on the hydraulic oil viscosity $v$ should be presented in expressions describing also the dependence of those losses on other parameters which influence them directly:

$$
\begin{gathered}
\mathrm{M}_{\mathrm{Mm}}=\mathrm{f}\left(\mathrm{M}_{\mathrm{M}}, \mathrm{n}_{\mathrm{M}}, v\right) \\
\mathrm{Q}_{\mathrm{Mv}}=\mathrm{f}\left(\Delta \mathrm{p}_{\mathrm{Mi}}, \mathrm{n}_{\mathrm{M}}, v\right) \\
\Delta \mathrm{p}_{\mathrm{Mp}}=\mathrm{f}\left(\mathrm{Q}_{\mathrm{M}}, v\right)
\end{gathered}
$$

The motor overall efficiency $\eta_{M}$, as a function of $M_{M}, n_{M}$ and $v$, is a product of $\eta_{\mathrm{Mm}}, \eta_{\mathrm{Mv}}$ and $\eta_{\mathrm{Mp}}$ efficiencies:

$$
\begin{gathered}
\eta_{M}=f\left(M_{M}, n_{M}, v\right)= \\
=\frac{P_{M u}}{P_{M c}}=\frac{M_{M} \omega_{M}}{\Delta p_{M} Q_{M}}=\frac{2 \Pi M_{M} n_{M}}{\Delta p_{M} Q_{M}}=\eta_{M m} \eta_{M v} \eta_{M p}
\end{gathered}
$$

where:

$$
\begin{aligned}
& \mathbf{P}_{\mathrm{Mu}} \quad \text { - the motor useful power, } \\
& \mathbf{P}_{\mathrm{Mc}} \quad \text { - the motor consumed power. }
\end{aligned}
$$

Each of the three efficiencies as a factor in the product describing the overall efficiency, is evaluated as a function of parameters directly influencing the respective losses and a function of parameter to which the losses are ,added":

- motor mechanical efficiency $\boldsymbol{\eta}_{\mathrm{Mm}}$ :

$$
\begin{gathered}
\eta_{M m}=\frac{P_{M u}}{P_{M i}}=\frac{M_{M} \omega_{M}}{\left(M_{M}+M_{M m}\right) \omega_{M}}= \\
=\frac{2 \Pi M_{M} n_{M}}{2 \Pi\left(M_{M}+M_{M m}\right) n_{M}}=\frac{M_{M}}{M_{M}+M_{M m}}=f\left(M_{M}, n_{M}, v\right)
\end{gathered}
$$

where:

$P_{\mathrm{Mi}}$ - the power indicated in the motor working chambers:

$$
\begin{gathered}
\mathrm{P}_{\mathrm{Mi}}=\Delta \mathrm{p}_{\mathrm{Mi}} \mathrm{q}_{\mathrm{Mt}} \mathrm{n}_{\mathrm{Mt}}= \\
=\left(\mathrm{M}_{\mathrm{M}}+\mathrm{M}_{\mathrm{Mm}}\right) \omega_{\mathrm{M}}=2 \Pi\left(\mathrm{M}_{\mathrm{M}}+\mathrm{M}_{\mathrm{Mm}}\right) \mathrm{n}_{\mathrm{M}}
\end{gathered}
$$

- motor volumetric efficiency $\boldsymbol{\eta}_{M v}$ :

$$
\begin{gathered}
\eta_{\mathrm{Mv}}=\frac{\mathrm{P}_{\mathrm{Mi}}}{\mathrm{P}_{\mathrm{Mci}}}=\frac{\Delta \mathrm{p}_{\mathrm{Mi}} \mathrm{q}_{\mathrm{Mt}} \mathrm{n}_{\mathrm{M}}}{\Delta \mathrm{p}_{\mathrm{Mi}}\left(\mathrm{q}_{\mathrm{Mt}} \mathrm{n}_{\mathrm{M}}+\mathrm{Q}_{\mathrm{Mv}}\right)}=\frac{\Delta \mathrm{p}_{\mathrm{Mi}} \mathrm{q}_{\mathrm{Mt}} \mathrm{n}_{\mathrm{M}}}{\Delta \mathrm{p}_{\mathrm{Mi}} \mathrm{Q}_{\mathrm{M}}}= \\
=\frac{\mathrm{q}_{\mathrm{Mt}} \mathrm{n}_{\mathrm{M}}}{\mathrm{q}_{\mathrm{Mt}} \mathrm{n}_{\mathrm{M}}+\mathrm{Q}_{\mathrm{Mv}}}=\frac{\mathrm{q}_{\mathrm{Mt}} \mathrm{n}_{\mathrm{M}}}{\mathrm{Q}_{\mathrm{M}}}=\mathrm{f}\left(\Delta \mathrm{p}_{\mathrm{Mi}}, \mathrm{n}_{\mathrm{M}}, v\right)
\end{gathered}
$$

where

$\mathrm{P}_{\mathrm{Mci}}$ - the power consumed in the motor working chambers:

$$
\mathrm{P}_{\mathrm{Mci}}=\Delta \mathrm{p}_{\mathrm{Mi}}\left(\mathrm{q}_{\mathrm{Mt}} \mathrm{n}_{\mathrm{M}}+\mathrm{Q}_{\mathrm{Mv}}\right)=\Delta \mathrm{p}_{\mathrm{Mi}} \mathrm{Q}_{\mathrm{M}}
$$

- motor pressure efficiency $\eta_{M p}$ :

$$
\begin{gathered}
\eta_{\mathrm{Mp}}=\frac{\mathrm{P}_{\mathrm{Mci}}}{\mathrm{P}_{\mathrm{Mc}}}=\frac{\Delta \mathrm{p}_{\mathrm{Mi}}\left(\mathrm{q}_{\mathrm{Mt}} \mathrm{n}_{\mathrm{M}}+\mathrm{Q}_{\mathrm{Mv}}\right)}{\left(\Delta \mathrm{p}_{\mathrm{Mi}}+\Delta \mathrm{p}_{\mathrm{Mp}}\right)\left(\mathrm{q}_{\mathrm{Mt}} \mathrm{n}_{\mathrm{M}}+\mathrm{Q}_{\mathrm{Mv}}\right)}=\frac{\Delta \mathrm{p}_{\mathrm{Mi}} \mathrm{Q}_{\mathrm{M}}}{\Delta \mathrm{p}_{\mathrm{M}} \mathrm{Q}_{\mathrm{M}}}= \\
=\frac{\Delta \mathrm{p}_{\mathrm{Mi}}}{\Delta \mathrm{p}_{\mathrm{Mi}}+\Delta \mathrm{p}_{\mathrm{Mp}}}=\frac{\Delta \mathrm{p}_{\mathrm{Mi}}}{\Delta \mathrm{p}_{\mathrm{M}}}=\mathrm{f}\left(\Delta \mathrm{p}_{\mathrm{Mi}}, \mathrm{Q}_{\mathrm{M}}, v\right)
\end{gathered}
$$

In order to present the motor volumetric efficiency $\eta_{\mathrm{Mv}}$ as a factor in the $\eta_{\mathrm{Mm}} \eta_{\mathrm{Mv}} \eta_{\mathrm{Mp}}$ product describing $\eta_{\mathrm{M}}$, i.e. to present $\eta_{\mathrm{Mv}}$ as a complex dependence on the $\left(\mathrm{M}_{\mathrm{M}}, \mathrm{n}_{\mathrm{M}}, v\right)$ parametrs describing $\eta_{\mathrm{M}}$ and dependent on the mechanical losses, the intensity $\mathrm{Q}_{\mathrm{Mv}}=\mathrm{f}\left(\Delta \mathrm{p}_{\mathrm{Mi}}, \mathrm{n}_{\mathrm{M}}, v\right)$ of volumetric losses in the working chambers should be determined with:

$$
\Delta \mathrm{p}_{\mathrm{Mi}}=\frac{2 \Pi\left(\mathrm{M}_{\mathrm{M}}+\mathrm{M}_{\mathrm{Mm}}\right)}{\mathrm{q}_{\mathrm{Mt}}}
$$

and with torque $\mathrm{M}_{\mathrm{Mm}}$ of mechanical losses in the „shaft - working chambers" assembly as an $\mathrm{M}_{\mathrm{Mm}}=\mathrm{f}\left(\mathrm{M}_{\mathrm{M}}, \mathrm{n}_{\mathrm{M}}, v\right)$ function.

In order to present the motor pressure efficiency $\eta_{\mathrm{Mp}}$ as a factor in the $\eta_{M m} \eta_{M v} \eta_{M p}$ product describing $\eta_{M}$, i.e. to present $\eta_{\mathrm{Mp}}$ as a complex dependence on the $\left(\mathrm{M}_{\mathrm{M}}, \mathrm{n}_{\mathrm{M}}, v\right)$ parameters describing $\eta_{\mathrm{M}}$ and dependent on the mechanical and volumetric losses in the motor, the pressure losses $\Delta \mathrm{p}_{\mathrm{Mp}}=\mathrm{f}\left(\mathrm{Q}_{\mathrm{M}}, v\right)$ in the channels must be determined with:

$$
\mathrm{Q}_{\mathrm{M}}=\mathrm{q}_{\mathrm{Mt}} \mathrm{n}_{\mathrm{M}}+\mathrm{Q}_{\mathrm{Mv}}
$$

then intensity $\mathrm{Q}_{\mathrm{Mv}}=\mathrm{f}\left(\Delta \mathrm{p}_{\mathrm{Mi}}, \mathrm{n}_{\mathrm{M}}, v\right)$ of volumteric losses in the working chambers must be determined with:

$$
\Delta \mathrm{p}_{\mathrm{Mi}}=\frac{2 \Pi\left(\mathrm{M}_{\mathrm{M}}+\mathrm{M}_{\mathrm{Mm}}\right)}{\mathrm{q}_{\mathrm{Mt}}}
$$

and the torque $\mathrm{M}_{\mathrm{Mm}}$ of mechanical losses in the ,shaft - working chambers" assembly must be determined as an $\mathrm{M}_{\mathrm{Mm}}=\mathrm{f}\left(\mathrm{M}_{\mathrm{M}}\right.$, $\left.\mathrm{n}_{\mathrm{M}}, v\right)$ function. 
The characteristic of the hydraulic motor overall efficiency $\eta_{\mathrm{M}}=\mathbf{f}\left(\mathrm{M}_{\mathrm{v}}, \mathrm{n}_{\mathrm{v}}, v\right)$ presents a complex picture as a product $\eta_{\mathrm{Mm}} \eta_{\mathrm{Mv}} \eta_{\mathrm{Mp}}$ of three efficiencies correctly described by:

- mechanical efficiency $\eta_{\mathrm{Mm}}=\mathrm{f}\left(\mathrm{M}_{\mathrm{M}}, \mathrm{n}_{\mathrm{M}}, v\right)$,

- volumetric efficiency $\eta_{\mathrm{Mv}}=\mathrm{f}\left(\Delta \mathrm{p}_{\mathrm{Mi}}, \mathrm{n}_{\mathrm{M}}, v\right)$,

- and pressure efficiency $\eta_{\mathrm{Mp}}=\mathrm{f}\left(\Delta \mathrm{p}_{\mathrm{Mi}}, \mathrm{Q}_{\mathrm{M}}, v\right)$

The picture of the hydraulic motor overall efficiency $\eta_{M}=f\left(M_{M}, n_{M}, v\right)$ must be supplemented by assessment of the motor operating field $\left(0 \leq \bar{\omega}_{M}<\bar{\omega}_{M_{\max }}, 0 \leq \overline{\mathrm{M}}_{\mathrm{M}}\left\langle\overline{\mathrm{M}}_{\mathrm{M}_{\max }}\right)\right.$ in the hydrostatic drive system, i.e. assessment of the range of $n_{M}$ and $\mathrm{M}_{\mathrm{M}}\left(\bar{\omega}_{\mathrm{M}}\right.$ and $\left.\overline{\mathrm{M}}_{\mathrm{M}}\right)$ parameters.

In the motor (and the drive system) $\left(0 \leq \bar{\omega}_{\mathrm{M}}\left\langle\bar{\omega}_{\mathrm{M}_{\max }}\right.\right.$, $0 \leq \overline{\mathrm{M}}_{\mathrm{M}}\left\langle\overline{\mathrm{M}}_{\mathrm{M}_{\max }}\right)$ operating field its current speed $\mathbf{n}_{\mathrm{M}}\left(\bar{\omega}_{\mathrm{M}}\right)$ and load $M_{M}\left(\bar{M}_{M}\right)$ are an effect of the demand of the motor (system) driven machine (device) and are independent of the losses in the hydraulic motor and in the motor driving hydrostatic system.

However, the hydraulic motor (system) operating field limit values $\mathrm{n}_{\mathrm{M} \max }\left(\bar{\omega}_{\mathrm{M}_{\max }}\right)$ and $\mathrm{M}_{\mathrm{M} \max }\left(\overline{\mathrm{M}}_{\mathrm{M}_{\max }}\right)$ depend on the maximum capacity of the motor driving system. The values $\mathrm{n}_{\mathrm{M} \max }\left(\bar{\omega}_{\mathrm{M}_{\max }}\right)$ and $\mathrm{M}_{\mathrm{M}_{\max }}\left(\overline{\mathrm{M}}_{\mathrm{M}_{\max }}\right)$ determine simultaneously the corresponding motor energy efficiency $\eta_{\mathrm{M}}$ and the overall system efficiency $\eta$.

The limit parameters of the hydrostatic drive system operation result from the pump theoretical capacity $\mathrm{Q}_{\mathrm{Pt}}$ and the system nominal working pressure $p_{n}$ as well as from the energy losses in the hydraulic motor, pump and conduits and also losses in the motor speed throttling control assembly (if it is installed). Therefore, the limit values $n_{M \max }\left(\bar{\omega}_{M_{\max }}\right)$ and $\mathrm{M}_{\mathrm{M} \max }\left(\overline{\mathrm{M}}_{\mathrm{M}_{\max }}\right)$ are also dependent on the working fluid viscosity $v$ changing in the $v_{\min } \leq v \leq v_{\max }$ range. The hydrostatically driven hydraulic motor operating field is also influenced by the $n_{p}=f\left(M_{p}\right)$ characteristic of the electric or combustion motor in the pump driving system.

Evaluation of the hydraulic motor overall efficiency $\eta_{M}=f\left(M_{M}, n_{M}, v\right)$ as a product $\eta_{M m} \eta_{M v} \eta_{M p}$ of three motor efficiencies should be performed by means of the mathematical models of losses and efficiencies, where the defined coefficients $k_{i}$ of energy losses in the motor and in the motor drive system are used.

Evaluation of the hydraulic motor energy efficiency is performed together with evaluation of the efficiency of a hydrostatic drive system where the motor is used [including also the energy efficiency of pump, conduits and the motor speed throttling control assembly (if it is used)].

In the proposed metod, based on the mathematical models of losses, each kind of energy losses is a function of parameters directly influencing the losses and independent of those losses.

Evaluated are the values of the $\mathrm{k}_{\mathrm{i}}$ coefficients of losses, relating the mechanical, volumetric and pressure losses in the hydraulic motor, pump and other system elements to the reference values of driving system nominal pressure $p_{n}$, theoretical capacity $\mathrm{Q}_{\mathrm{pt}}$ of the system driving pump, theoretical speed $\mathrm{n}_{\mathrm{Mt}}$ and theoretical torque $\mathrm{M}_{\mathrm{Mt}}$ of the motor shaft as well as the theoretical speed $n_{p t}$ and theoretical torque $\mathrm{M}_{\mathrm{Pt}}$ of the pump shaft. The $\mathrm{k}_{\mathrm{i}}$ coefficients are determined at the hydraulic oil reference viscosity $v_{n}$. At the same time the impact is determined of the viscosity ratio $v / v_{\mathrm{n}}$ in the $v_{\min } \leq v \leq v_{\max }$ range on the $\mathrm{k}_{\mathrm{i}}$ coefficient values.

The method allows to evaluate the values and proportions of mechanical, volumetric and pressure losses in the motor, pump, conduits and in the throttling assembly (if installed), as well as the dependence on the hydraulic oil viscosity $v$.
The energy investigations of a pump and hydraulic motor as independent machines are limited to determination of the $\mathrm{k}_{\mathrm{i}}$ coefficients of losses in them. The energy efficiency characteristics of those machines are determined in parallel with efficiency evaluation of the system where they are used.

The knowledge of $\mathrm{k}_{\mathrm{i}}$ coefficients of the mechanical, volumetric and pressure losses in the drive system elements allows to obtain, with the numerical method, the characteristics of the hydrostatic drive system overall efficiency, pump efficiency, hydraulic motor efficiency, conduit efficiency and the motor speed throttling control assembly (if it is used) efficiency in the motor (system) $\left(0 \leq \bar{\omega}_{M}\left\langle\bar{\omega}_{M_{\max }}, 0 \leq \overline{\mathrm{M}}_{\mathrm{M}}\left\langle\overline{\mathrm{M}}_{\mathrm{M}_{\max }}\right)\right.\right.$ operating field at a selected ratio $v / v_{n}$ of the hydraulic oil viscosity and the reference viscosity.

Characteristics of energy efficiency of the pump and hydraulic motor with the determined constant coefficients $\mathrm{k}_{\mathrm{i}}$ of losses and also of efficiency of the conduits are different in hydrostatic systems with different motor speed control structures.

Characteristics of the overall efficiency of elements used in a hydrostatic drive system: pump $\eta_{\mathrm{p}}$, hydraulic motor $\eta_{\mathrm{M}}$, conduits $\eta_{\mathrm{C}}$ and throttling control assembly (if it is used) structural efficiency $\boldsymbol{\eta}_{\text {st }}$ are defined as functions of the hydraulic motor (system) speed coefficient $\bar{\omega}_{\mathrm{M}}$ and load coefficient $\bar{M}_{M}$ and the hydraulic oil viscosity ratio $v / v_{n}$.

At the same time the hydraulic motor $\left(0 \leq \bar{\omega}_{\mathrm{M}}\left\langle\bar{\omega}_{\mathrm{M}_{\max }}^{\mathrm{n}^{\circ}}\right.\right.$, $0 \leq \overline{\mathrm{M}}_{\mathrm{M}}\left\langle\overline{\mathrm{M}}_{\mathrm{M}_{\max }}\right)$ operating field in the hydrostatic drive system is determined at the selected ratio $v / v_{n}$ of the hydraulic oil viscosity to the reference viscosity.

The method is precise by definition and simple in use. It simplifies the laboratory investigation of pumps, hydraulic motors and hydrostatic drive systems. It allows to seek for energy saving solutions of pumps and hydraulic motors. It allows also to evaluate the overall energy efficiency of the drive and finding energy saving hydrostatic drive system structures.

\section{CONCLUSIONS}

1. The methods of investigating the rotational hydraulic motor losses and energy efficiency, used in scientific research and industrial practice, give incorrect evaluations, because:

- the losses and efficiencies are evaluated as functions of parameters which depend on those losses or as functions of parameters, which have no direct impact on the losses,

- the mechanical, volumetric and pressure losses and the corresponding energy efficiencies are presented as dependent on the same parameters, although in fact each of those losses is a function of different parameters and is a different function of the hydraulic oil viscosity $v$.

2. The basic reason for the incorrect evaluation are common views on the methods of carrying out the investigations and on the method of defining the energy losses in pumps and hydraulic motors. The method is based on the traditional understanding of the hydrostatic drive system energy balance illustrated by the Sankey diagram of the power decrease in the system in the direction of power flow $[3 \div 6,15,17,19,21,22]$.

3. Diagram of power increase in a power transmission system opposite to the direction of power flow replaces the Sankey diagram of power decrease in the direction of power flow.

4.The characteristic of the hydraulic motor overall efficiency $\eta_{\mathrm{M}}=\mathrm{f}\left(\mathrm{M}_{\mathrm{M}}, \mathrm{n}_{\mathrm{M}}, v\right)$ as a product $\eta_{\mathrm{Mm}} \eta_{\mathrm{Mv}} \eta_{\mathrm{Mp}}$ of three efficiencies correctly described by the characteristics of the mechanical 
efficiency $\eta_{\mathrm{Mm}}=\mathrm{f}\left(\mathrm{M}_{\mathrm{M}}, \mathrm{n}_{\mathrm{M}}, v\right)$, volumetric efficiency $\eta_{\mathrm{Mv}}=\mathrm{f}\left(\Delta \mathrm{p}_{\mathrm{Mi}}, \mathrm{n}_{\mathrm{M}}, v\right)$ and pressure efficiency $\eta_{\mathrm{Mp}}=\mathrm{f}\left(\Delta \mathrm{p}_{\mathrm{Mi}}\right.$, $\left.\mathrm{Q}_{\mathrm{M}}, v\right)$, is very complex.

5. Picture of the hydraulic motor overall efficiency $\eta_{M}=f\left(M_{M}, n_{M}, v\right)$ must be supplemented by evaluation of the motor $\left(0 \leq \bar{\omega}_{\mathrm{M}}<\bar{\omega}_{\mathrm{M}_{\max }}, 0 \leq \overline{\mathrm{M}}_{\mathrm{M}}<\overline{\mathrm{M}}_{\mathrm{M}_{\max }}\right)$ operating field in the hydrostatic drive system, i.e. of the $n_{M}$ and $M_{M}$ $\left(\bar{\omega}_{M}\right.$ and $\left.\bar{M}_{M}\right)$ range. The hydraulic motor operating field limit values $\mathrm{n}_{\mathrm{M} \max }\left(\bar{\omega}_{\mathrm{M}_{\max }}\right)$ and $\mathrm{M}_{\mathrm{M} \max }\left(\overline{\mathrm{M}}_{\mathrm{M}_{\max }}\right)$ depend on the maximum capacity of the motor driving hydrostatic system. That capacity is a result of the pump theoretical capacity $\mathrm{Q}_{\mathrm{Pt}}$, system nominal pressure $\mathrm{p}_{\mathrm{n}}$ and energy losses in all the system elements, which depend also on the used motor speed control structure.

6. Evaluation of the hydraulic motor overall efficiency $\eta_{\mathrm{M}}=\mathrm{f}\left(\mathrm{M}_{\mathrm{M}}, \mathrm{n}_{\mathrm{M}}, v\right)$ as a product $\eta_{\mathrm{Mm}} \eta_{\mathrm{Mv}} \eta_{\mathrm{Mp}}$ of the three motor efficiency should be based on the mathematical models of losses and efficiencies where coefficients $k_{i}$ of the energy losses in the motor and in the motor driving system are used. Proposed evaluation of the hydraulic motor efficiency is performed together with evaluation of the energy efficiency of pump, efficiency of conduits and efficiency of the throttling control assembly (if it is used) as well as the overall efficiency of the hydrostatic drive system, where the pump, motor, conduits and control system assembly are applied.

7. Evaluated are the values of $\mathrm{k}_{\mathrm{i}}$ coefficients of losses relating the mechanical, volumetric and pressure losses in the hydraulic motor, pump and the whole system to the reference values: theoretical capacity $\mathrm{Q}_{\mathrm{pt}}$ of the system driving pump, system nominal pressure $p_{n}$, motor shaft theoretical speed $\mathrm{n}_{\mathrm{Mt}}$ and theoretical torque $\mathrm{M}_{\mathrm{Mt}}$ as well as the theoretical speed $\mathrm{n}_{\mathrm{Pt}}$ and theoretical torque $\mathrm{M}_{\mathrm{Pt}}$ of the pump shaft. The $\mathrm{k}_{\mathrm{i}}$ coefficients of losses are determined at the hydraulic oil reference viscosity. At the same time the impact of the oil viscosity ratio $v / v_{n}$ (viscosity in the $v_{\text {mi }}$ $\leq v \leq v_{\text {max }}$ range) impact on the values of $k_{i}$ coefficients of losses is determined.

8. The method allows to evaluate the values and proportions of the mechanical, volumetric and pressure losses in the hydraulic motor, pump and the system and also their dependence on the hydraulic oil viscosity $v$.

9. Energy investigations of the pump and hydraulic motor as independent machines are limited to determination of the $\mathrm{k}_{\mathrm{i}}$ coefficients of losses. The energy efficiency characteristics of those machines are determined in parallel with evaluation of efficiency of a hydrostatic system where the machines are used.

10. Knowledge of the values of $\mathrm{k}_{\mathrm{i}}$ coefficients of losses allows to obtain, by a numerical metod, of the hydraulic motor efficiency $\eta_{M}=f\left(\bar{\omega}_{M}, \bar{M}_{M}, v / v_{n}\right)$, pump efficiency $\eta_{P}=f\left(\bar{\omega}_{M}, \bar{M}_{M}, v / v_{n}\right)$, conduit efficiency $\eta_{C}=f\left(\bar{\omega}_{M}, \bar{M}_{M}, v / v_{n}\right)$, throttling control assembly (if used) structural efficiency $\eta_{\mathrm{st}}$ $=\mathrm{f}\left(\bar{\omega}_{\mathrm{M}}, \overline{\mathrm{M}}_{\mathrm{M}}, v / v_{\mathrm{n}}\right)$ and the hydrostatic drive system overall efficiency $\eta=\mathrm{f}\left(\bar{\omega}_{\mathrm{M}}, \overline{\mathrm{M}}_{\mathrm{M}}, v / v_{\mathrm{n}}\right)$ in the hydraulic motor (system) $\left(0 \leq \bar{\omega}_{\mathrm{M}}<\bar{\omega}_{\mathrm{M}_{\max }}, 0 \leq \overline{\mathrm{M}}_{\mathrm{M}}<\overline{\mathrm{M}}_{\mathrm{M}_{\max }}\right)$ operating field and at the selected ratio $v / v$ of hydraulic oil viscosity.

11. The method is precise by definition and simple in use. It simplifies the laboratory investigations of pumps, hydraulic motors and hydrostatic drive systems. It allows to evaluate the characteristics of the system overall energy efficiency as well as to seek for the energy saving hydrostatic drive structures.

12. The method is a proposition for the pump, hydraulic motor, hydrostatic drive and control system designers and manufacturers. It is in the process of development.

\section{BIBLIOGRAPHY}

1. Electric drives improve load cycle performance. MacGREGOR News 154 Autumn 2006

2. Electric drives advantages are available to all ship types. MacGREGOR News 161 Autumn 2010

3. Paszota Z.: Direction of increase of power stream in the hydrostatic drive and control system. Graphical presentation of the power of energy losses and power developed in the elements of hydrostatic drive and control system. Part I-Rotational hydraulic motor speed series throttling control systems. (in Polish), Napędy i sterowanie, scientific monthly, No 10 (114), October 2008

4. Paszota Z.: Direction of increase of power stream in the hydrostatic drive and control system. Graphical presentation of the power of energy losses and power developed in the elements of hydrostatic drive and control system. Part II - Rotational hydraulic motor speed parallel throttling control and volumetric control systems. (in Polish), Napędy i sterowanie, scientific monthly, No 11 (115), November 2008

5. Paszota Z.: Graphical presentation of the power of energy losses and power developed in the elements of hydrostatic drive and control system. Part I - Rotational hydraulic motor speed series throttling control systems. Polish Maritime Research 03/2008

6. Paszota Z.: Graphical presentation of the power of energy losses and power developed in the elements of hydrostatic drive and control system. Part II - Rotational hydraulic motor speed parallel throttling control and volumetric control systems. Polish Maritime Research 04/2008

7. Paszota Z.: The operating field of a hydrostatic drive system. Chapter in the monograph: ,Research, design, production and operation of hydraulic systems" (in Polish), Adam Klich, Antoni Kozieł and Edward Palczak editors. „Cylinder” Library. Komag Mining Mechanisation Centre, Gliwice 2009

8. Paszota Z.: Parameters of the energy efficiency investigations of pumps and hydraulic motors. The operating field of a hydrostatic drive system. (in Polish), Napędy i sterowanie, scientific monthly, No 11 (127), November 2009

9. Paszota Z.: The operating field of a hydrostatic drive system parameters of the energy efficiency investigations of pumps and hydraulic motors. Polish Maritime Research 04 / 2009

10.Technical matter of the Hägglunds Company: Product Manual VIKING EN397-3a 1999

11. Technical matter of the Bosch Rexroth AG Company: RE 91 604/06.03 I AGVM

12.Technical matter of the Parker Hannifin Company: Catalogue HY30-8223/UK

13.Technical matter of the SAUER DANFOSS Company: Technical Information 520L0440·Rev AD·Dec 2009

14. Technical matter of the LABORATOIRE HYDRO LEDUC Company: Efficiency M series motors

15.Paszota Z.: Energy losses in a rotational hydraulic motor definitions and relations for evaluation of the efficiency of motor and hydrostatic drive. Chapter in the monograph: ,Research, design, production and operation of hydraulic systems" (in Polish), Adam Klich, Antoni Kozieł and Edward Palczak editors. „Cylinder” Library. Komag Mining Mechanisation Centre, Gliwice 2010

16.Paszota Z.: Theoretical and mathematical models of the torque of mechanical losses in a hydraulic rotational motor for hydrostatic drive. Chapter in the monograph: ,Research, design, production and operation of hydraulic systems" (in Polish), Adam Klich, Antoni Kozieł and Edward Palczak editors. „Cylinder” Library. Komag Mining Mechanisation Centre, Gliwice 2010

17.Paszota Z.: Energy losses in a rotational hydraulic motor - definitions and relations for evalution of the efficiency of motor and hydrostatic drive. (in Polish), Napędy i sterowanie, scientific monthly, No 10(138), October 2010

18.Paszota Z.: Theoretical and mathematical models of the torque of mechanical losses in a hydraulic rotational motor for hydrostatic drive. (in Polish), Napędy i sterowanie, scientific monthly, No 11(139), November 2010 
19.Paszota Z.: Energy losses in the hydraulic rotational motordefinitions and relations for evaluation of the efficiency of motor and hydrostatic drive. Polish Maritime Research 2/2010

20.Paszota Z.: Theoretical and mathematical models of the torque of mechanical losses in a hydraulic rotational motor for hydrostatic drive. Polish Maritime Research 3/2010

21.Paszota Z.: Hydrostatic drives as safe and energy saving machines. (in Polish), Napędy i sterowanie, scientific monthly, No 1(141), January 2011

22.Paszota Z.: Hydrostatic drives as safe and energy saving machines. (in Polish), Proceedings of the „Innovative machines and Technologies - Safety" conference, Szczyrk $03-04$ February 2011

\section{CONTACT WITH THE AUTHOR}

Prof. Zygmunt Paszota Faculty of Ocean Engineering and Ship Technology

Gdansk University of Technology Narutowicza 11/12 80-233 Gdansk, POLAND e-mail: zpaszota@pg.gda.pl 